
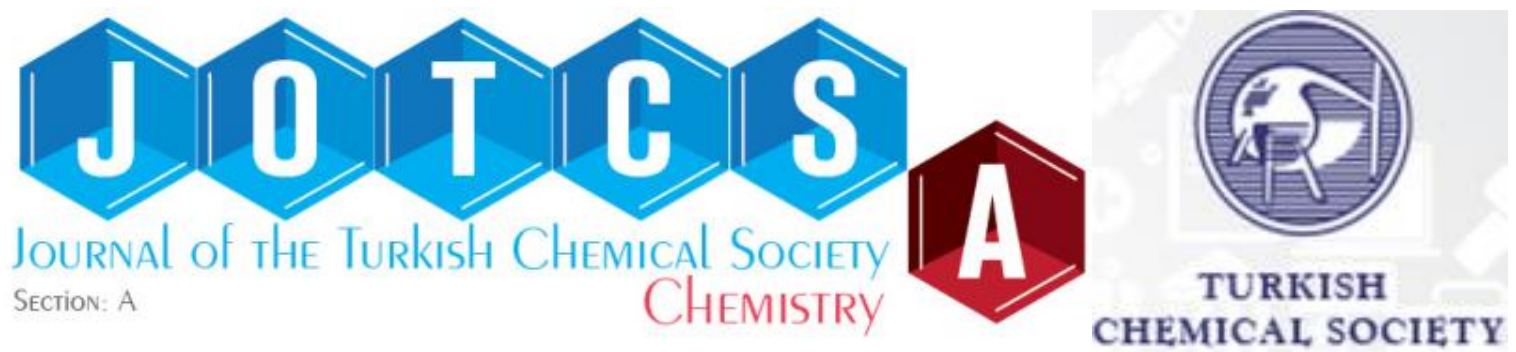

\title{
PRODUCTION AND CHARACTERIZATION OF ACTIVATED CARBON FROM POMEGRANATE PULP BY PHOSPHORIC ACID
}

\author{
Eylem PEHLIVAN ${ }^{1}$
}

\author{
1. Faculty of Engineering, Department of Chemical and Process Engineering, Bilecik Şeyh \\ Edebali University, Bilecik, Turkey
}

(This article first appeared in PPM2017 and was accepted as a non-peer-reviewed manuscript to be published in JOTCSA)

\begin{abstract}
In this study, samples of activated carbon were prepared from pomegranate pulp by chemical activation. $\mathrm{H}_{3} \mathrm{PO}_{4}$ was used as chemical activation agent and three impregnation ratios (50-100-200\%) by mass were applied on biomass at impregnation times of 24 and 48 hours. Carbonization is applied to impregnated biomass samples under $\mathrm{N}_{2}$ sweeping gas in a fixed bed reactor at 500 and $700{ }^{\circ} \mathrm{C}$. For determination of chemical and physical properties of the obtained activated carbons; elemental analysis was applied to determine the elemental composition ( $\mathrm{C}, \mathrm{H}, \mathrm{N}, \mathrm{O}$ ) and FT-IR spectra was used to analyze the functional groups. BET equation was used to calculate the surface areas of activated carbons. For understanding the changes in the surface structure, activated carbons were conducted to Scanning Electron Microscopy (SEM). Maximum BET surface area $\left(840 \mathrm{~m}^{2} / \mathrm{g}\right)$ was reached with the activated carbon generated using $200 \% \quad \mathrm{H}_{3} \mathrm{PO}_{4}$ impregnated biomass sample, at a carbonization temperature of $700{ }^{\circ} \mathrm{C}$ and impregnation time of 48 hours. Experimental results showed that impregnation ratio have a significant effect on the pore structure of activated carbon and pomegranate pulp seems to be an alternative precursor for commercial activated carbon production.
\end{abstract}

Keywords: Chemical activation, carbonization, characterization, activated carbon, biomass.

Cite This: Pehlivan E. PRODUCTION AND CHARACTERIZATION OF ACTIVATED CARBON FROM POMEGRANATE PULP BY PHOSPHORIC ACID. Journal of the Turkish Chemical Society, Section A: Chemistry. 2018; 5(sp. is. 1):1-8.

Corresponding Author. E-mail: eylem.onal@bilecik.edu.tr 


\section{INTRODUCTION}

Activated carbon is a black charcoal-like material, which has a well-developed pore structure, which leads to its large surface area; in addition, it possesses good mechanical strength. Activated carbon is commonly used as adsorbent in wastewater treatment and gas removal as well as a catalyst. Commercial activated carbon is normally obtained by using coal as the precursor, making it very costly and hence requiring searches for cheaper substitutes, mainly from biomass. Agricultural waste is gaining credence as a suitable precursor for the preparation of activated carbon to be used as an adsorbent due to its easy availability and nearly-zero or low cost [Senthilkumar, et al., 1999].

In this study, activated carbons were prepared from pomegranate pulp by chemical activation with $\mathrm{H}_{3} \mathrm{PO}_{4}$. The yields, specific surface areas, pore volumes and, pore sizes of the activated carbons were determined. The influence of the different impregnation ratios, activation times and the carbonization temperatures on surface chemistry was investigated using instrumental methods such as elemental analysis, FT-IR, BET and SEM.

\section{MATERIALS AND METHODS}

Pomegranate pulp have been supplied by a fruit factory in the region of western Turkey. It was dried at room temperature. Drying was timed up to obtaining a constant weight. After drying raw material was ground in a high-speed rotary cutting mill and stored in a cool and dark room. Average particle size in $0.5245 \mathrm{~mm}$ was used for preparation of activated carbon. The characteristics of the raw material are presented in Table 1.

Table 1: Properties of the pomegranate pulp.

\begin{tabular}{llll}
\hline Proximate analysis & \% & Ultimate analysis & \% \\
\hline Moisture & 8.38 & $\mathrm{C}$ & 48.80 \\
Volatile matters & 76.36 & $\mathrm{H}$ & 5.36 \\
Ash & 2.51 & $\mathrm{~N}$ & 1.75 \\
Fixed carbon & 13.64 & $\mathrm{O} *$ & 44.09 \\
Bulk density $\left(\mathrm{kg} / \mathrm{m}^{3}\right)$ & 500 & Empirical formula & $\mathrm{CH}_{1.1 .31} \mathrm{~N}_{0.031} \mathrm{O}_{0.68}$ \\
Component analysis & $\%$ & $\mathrm{H} / \mathrm{C}$ & 1.31 \\
Extractive material & 3.70 & O/C & 0.68 \\
Hemicellulose & 15.56 & Higher calorific value $(\mathrm{Mj} / \mathrm{kg})$ & 18.88 \\
Lignin & 46.56 & & \\
Cellulose* & 35.52 & & \\
\hline
\end{tabular}

Raw material was directly impregnated with chemical activation agent. Ground and sieved pomegranate pulp were treated with $\mathrm{H}_{3} \mathrm{PO}_{4}$ solutions at room temperature in three different weight ratios as $0.5 / 1-1 / 1-2 / 1$. Continuous mixing of the precursor with chemicals for 24 and $48 \mathrm{~h}$ was maintained by using a magnetic stirrer. After mixing, solutions were allowed to dry at room temperature for $24 \mathrm{~h}$ and then dried at $85{ }^{\circ} \mathrm{C}$ for $72 \mathrm{~h}$ in a temperature controlled oven to prepare impregnated samples. Impregnated samples were carbonized in a stainless steel fixed bed reactor at 500 and $700{ }^{\circ} \mathrm{C}$ under nitrogen $\left(\mathrm{N}_{2}\right)$ flow of $100 \mathrm{~cm}^{3} / \mathrm{min}$ and at a heating rate of $10{ }^{\circ} \mathrm{C} / \mathrm{min}$ and held at this temperature for $1 \mathrm{~h}$. After being cooled, all the carbonized 
samples were washed several times with hot water until pH became neutral and finally washed with cold water to remove residual chemicals. Washed samples were dried at $105{ }^{\circ} \mathrm{C}$ for $24 \mathrm{~h}$ to obtain the final activated carbons. Results in Table 2 indicate that both the concentrations and carbonization temperatures influenced the yields of the activated carbons.. An increase in the reagent concentration at the same temperatures resulted in a decrease in the yields of the activated carbons. An increase in the temperature at the same concentrations led to a decrease in the yields of the activated carbons.

Yield of activated carbon $w t \%=\frac{\text { Final weight of activated carbon }}{\text { Initial weight of pomegranate pulp }} \times 100$ (1)

Table 2: Nomenclature, preparation conditions and yields of activated carbon.

\begin{tabular}{lllll}
\hline $\begin{array}{l}\text { Activated } \\
\text { Carbon Name }\end{array}$ & $\begin{array}{l}\text { Carbonization } \\
\text { temperature }\left({ }^{\circ} \mathbf{C}\right)\end{array}$ & $\begin{array}{l}\text { Impregnation } \\
\text { ratio }(\mathbf{g} / \mathbf{g})\end{array}$ & $\begin{array}{l}\text { Impregnation time } \\
(\text { hours) }\end{array}$ & $\begin{array}{l}\text { Yield } \\
(\%)\end{array}$ \\
\hline AC1 & 500 & $0,5 / 1$ & 24 & 23,25 \\
AC2 & 500 & $1 / 1$ & 24 & 12,32 \\
AC3 & 500 & $2 / 1$ & 24 & 6,30 \\
AC4 & 500 & $0,5 / 1$ & 48 & 28,70 \\
AC5 & 500 & $1 / 1$ & 48 & 10,21 \\
AC6 & 500 & $2 / 1$ & 48 & 2,25 \\
AC7 & 700 & $0,5 / 1$ & 24 & 24,91 \\
AC8 & 700 & $1 / 1$ & 24 & 12,08 \\
AC9 & 700 & $2 / 1$ & 24 & 4,62 \\
AC10 & 700 & $0,5 / 1$ & 48 & 24,00 \\
AC11 & 700 & $1 / 1$ & 48 & 13,46 \\
AC12 & 700 & $2 / 1$ & 48 & 4,60 \\
\hline
\end{tabular}

Table 3: Surface areas and pore volumes of activated carbons.

\begin{tabular}{|c|c|c|c|c|c|c|c|c|}
\hline$A C$ & $\begin{array}{l}S_{B E T} \\
\left(m^{2} / g\right)\end{array}$ & $\begin{array}{l}S_{\text {mikro }} \\
\left(m^{2} / g\right)\end{array}$ & $\begin{array}{l}S_{\text {ext }} \\
\left(m^{2} / g\right)\end{array}$ & $\begin{array}{l}V_{\text {total }} \\
\left(\mathrm{cm}^{3} / \mathrm{g}\right)\end{array}$ & $V_{\text {micro }}$ & & & \\
\hline$\left(\mathrm{cm}^{3} / \mathrm{g}\right)$ & $V_{\text {meso }}$ & & & & & & & \\
\hline$\left(\mathrm{cm}^{3} / \mathrm{g}\right)$ & $\%$ Smicro & $D_{p}\left({ }^{\circ} A\right)$ & & & & & & \\
\hline \multirow[t]{2}{*}{$\mathrm{AC} 1$} & 352 & 183 & 169 & 0.2153 & & & & \\
\hline & 0.1313 & 0.084 & 52 & 170 & & & & \\
\hline AC2 & 617 & 443 & 174 & 0.3948 & 0,3178 & 0.077 & 72 & 97 \\
\hline AC3 & 830 & 735 & 95 & 0.7313 & 0,6953 & 0.036 & 88 & 72 \\
\hline AC4 & 266 & 171 & 95 & 0.1505 & 0.0715 & 0.079 & 64 & 225 \\
\hline AC5 & 602 & 335 & 267 & 0.3630 & 0.2403 & 0.1227 & 55 & 99 \\
\hline AC6 & 830 & 652 & 178 & 0.6150 & 0.5380 & 0.077 & 78 & 77 \\
\hline$A C 7$ & 378 & 221 & 157 & 0.2193 & 0.1174 & 0.1019 & 58 & 158 \\
\hline AC8 & 597 & 394 & 203 & 0.3953 & 0.3043 & 0.091 & 65 & 100 \\
\hline AC9 & 869 & 728 & 141 & 0.8167 & 0.7727 & 0.044 & 86 & 71 \\
\hline$A C 10$ & 293 & 208 & 85 & 0.1626 & 0.067 & 0.095 & 70 & 204 \\
\hline $\mathrm{AC} 11$ & 669 & 383 & 286 & 0.3746 & 0.2437 & 0.1309 & 57 & 89 \\
\hline $\mathrm{AC} 12$ & 819 & 664 & 155 & 0.6868 & 0.6214 & 0.065 & 81 & 73 \\
\hline
\end{tabular}

\section{Characterization of the activated carbons}

The carbon, hydrogen, nitrogen, and oxygen (by difference) contents of the pomegranate pulp and activated carbons were measured using a Carlo Erba EA 1108 model Elemental Analyzer. Surface areas of each activated carbon were calculated from $\mathrm{N}_{2}$ adsorption isotherms by using 
BET (Brunauer-Emmett-Teller) method with Quantachrome Autosorb 1 analyzer. The adsorption data of the total pore volume $\left(V_{\text {total }}\right)$ were determined from the amount of nitrogen adsorbed at a relative pressure of 0.995 and calculated with the manufacturer's software. The same adsorption data were also used for calculation of the micropore volume by the t-plot method. The mesopore volume $\left(V_{\text {meso }}\right)$ was calculated by subtracting $V_{\text {micro }}$ from $V_{\text {total }}\left(V_{\text {meso }}=\right.$ $V_{\text {total }}-V_{\text {micro }}$ ). The functional groups on the surface of the activated carbon were determined by Bruker Tensor 27 Model FTIR spectrometer. The spectrum was obtained over the range of $400-4,000 \mathrm{~cm}^{-1}$. The surface morphologies were studied by SEM. The SEM images were obtained using Zeiss Evo 50 SEM.

\section{RESULTS AND DISCUSSION}

BET surface area of activated carbon is important because, like other physical and chemical characteristics, it may strongly affect the reactivity and combustion behavior. The higher surface areas are probably due to the opening of the restricted pores [Ioannidou and Zabaniotou, 2007]. BET surface area of activated carbons are shown in Table 3. It can be seen that surface area increases with impregnation ratio and carbonization temperature. The highest surface area $\left(869 \mathrm{~m}^{2} / \mathrm{g}\right.$ ) was obtained having $2 / 1$ impregnation ratio and $700{ }^{\circ} \mathrm{C}$ temperature which is relatively high surface area for an activated carbon. The effect of different activation temperature impregnation ratios and times on total pore volume, micropore volume and micropore area for the activated carbons with the highest surface areas are given in Table 4. It was seen that, microporous structure is well developed for the activated carbon produced activation with increasing impregnation ratio up to $2 / 1$. The optimum impregnation ratio to get higher surface area and pore volume was determined as $2 / 1 \%$, where the highest surface area of $839 \mathrm{~m}^{2} / \mathrm{g}$ with a pore volume of $0.8167 \mathrm{~cm}^{3} / \mathrm{g}$ were obtained activated carbon.

The elemental analysis results of the activated carbons obtained are shown in Table 4. Compared to the pomegranate pulp, all carbon samples had higher contents of $\mathrm{C}$ and lower contents of $\mathrm{H}$ and $\mathrm{O}$. It can be said that chemical activation accelerated the removal of $\mathrm{H}$ and $\mathrm{O}$ and this resulted in an increased $\mathrm{C}$ content as expected. 
Table 4: Elemental analysis of activated carbons.

\begin{tabular}{lllll}
\hline & $(\%) \mathrm{N}$ & $(\%) \mathrm{C}$ & $(\%) \mathrm{H}$ & $(\%) \mathrm{O}$ \\
\hline Raw material & 1.75 & 48.80 & 6.96 & 42.49 \\
AC1 & 2.07 & 67.26 & 4.10 & 26.52 \\
AC2 & 1.50 & 68.63 & 4.18 & 25.67 \\
AC3 & 1.42 & 69.11 & 3.77 & 25.69 \\
AC4 & 1.69 & 71.59 & 4.59 & 22.11 \\
AC5 & 1.54 & 70.16 & 4.80 & 23.48 \\
AC6 & 1.47 & 65.83 & 4.71 & 27.96 \\
AC7 & 1.47 & 70.30 & 3.49 & 24.73 \\
AC8 & 1.23 & 64.18 & 3.36 & 31.21 \\
AC9 & 1.10 & 63.00 & 3.31 & 32.58 \\
AC10 & 1.25 & 67.78 & 3.14 & 27.81 \\
AC11 & 1.11 & 63.54 & 3.17 & 32.15 \\
AC12 & 0.98 & 64.53 & 2.67 & 31.80 \\
\hline
\end{tabular}

Scanning electron microscopy (SEM) technique was used to observe the surface physical morphology of the samples. SEM micrographs of the pomegranate pulp and the produced activated carbon (AC9) were given in Figure $2 a$ and b. From Figure $2 a$, it is clear that the pomegranate pulp has fibrous structure with smooth surface. $\mathrm{H}_{3} \mathrm{PO}_{4}$ activation has substantial effect on the pomegranate pulp with impregnation ratio of $2 / 1$ shows cavities on their external surface that improve the porosity. Different pore sizes and shapes were observed on the activated carbon surface because of depolymerization and subsequent release of volatile organic substances from carbonization.
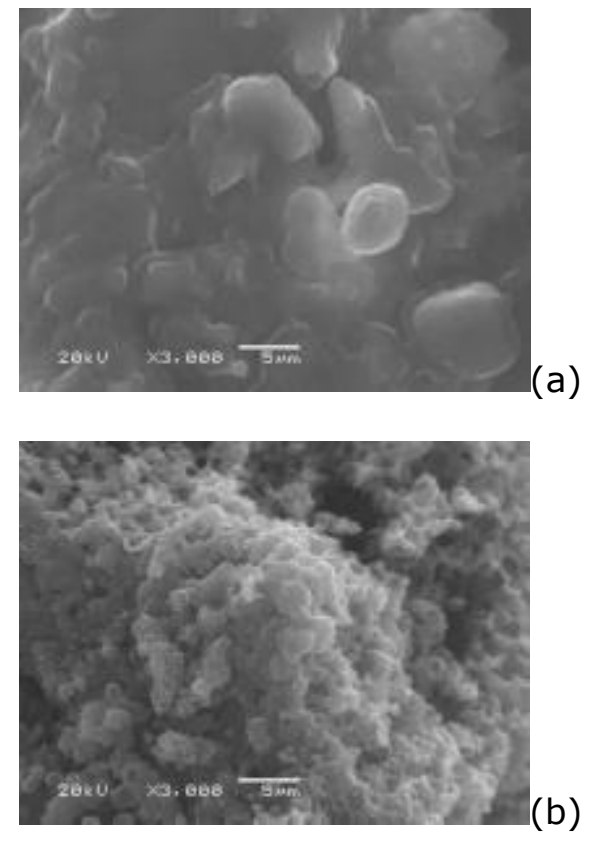

Figure 1: SEM images pomegranate pulp (a) and its activated carbon (b).

Functional groups are very important characteristics of the activated carbons, because they determine the surface properties of the carbons and their quality. FT-IR spectroscopy in its various forms is an important and forceful technique which can give useful information about structures. It can provide basic spectra of activated carbons, especially for determination of 
types and intensities of their surface functional groups [El-Hendawy, 2006]. FT-IR spectrum of pomegranate pulp is given in Figure. 3 . The broad and flat band at about $3300-3400 \mathrm{~cm}^{-1}$ shows the presence of $\mathrm{OH}$ stretching vibration of alcohol, phenol or carboxylic acid. The strong band at $2950-2800 \mathrm{~cm}^{-1}$ represents $\mathrm{C} \mathrm{H}$ stretching vibration in methyl group. Another strong band at $1750 \mathrm{~cm}^{-1}$ is ascribed to $\mathrm{C}=\mathrm{O}$ vibrations probably from esters, ketones or aliphatic acids. The band at $1620 \mathrm{~cm}^{-1}$ can be ascribed to $\mathrm{C}=\mathrm{C}$ aromatic ring stretching vibration. The peak at $1245-1155 \mathrm{~cm}^{-1}$ may be assigned to the hydrogen-bonded $\mathrm{P}=\mathrm{O}, \mathrm{O} \mathrm{C}$ stretching vibrations in $\mathrm{P}-\mathrm{O}-\mathrm{C}$ linkage, and $\mathrm{P}=\mathrm{O}(\mathrm{OH})$. The very strong band at $1020 \mathrm{~cm}^{-1}$ represents $\mathrm{C}-\mathrm{O}$ stretching vibrations. The weaker bands between 765 and $530 \mathrm{~cm}^{-1}$ are ascribed to aromatic structures. Figure. 4 represents the FTIR spectra. The spectra are approximately very similar for the activated carbons; however they different from raw material, which is a result of the chemical and thermal treatment Some bands disappeared or weakened during the activated carbon preparation including the impregnation and the activation; in particular, the bands located in two regions between 3,600 and $2,800 \mathrm{~cm}^{-1}$ and between 800 and $400 \mathrm{~cm}^{-1}$. The first peak at $3,300 \mathrm{~cm}^{-1}$ is ascribed to $\mathrm{OH}$ stretching vibration in hydroxyl groups. This peak is stronger for the pomegranate pulp and has weakened for the activated carbon.Two strong bands observed at 2,920 and 2,860 $\mathrm{cm}^{-1}$ are assigned to asymmetric $\mathrm{C}-\mathrm{H}$ and symmetric $\mathrm{C}-\mathrm{H}$ bands, respectively, present in alkyl groups such as methyl and methylene groups. However, this band disappeared in the activated carbon. These bands were visible in raw material, but not in activated carbon.

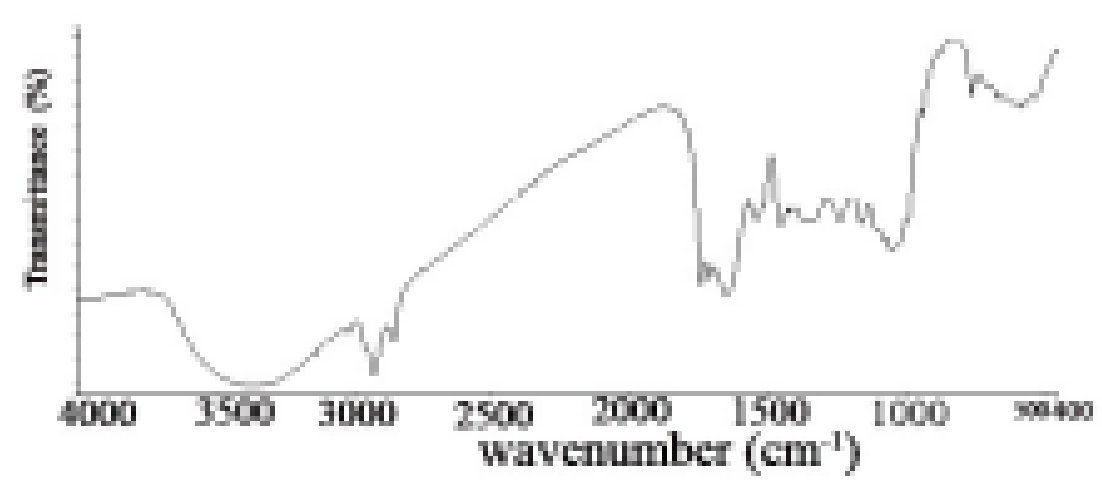

Figure 2: FT-IR spectrum of pomegranate pulp. 


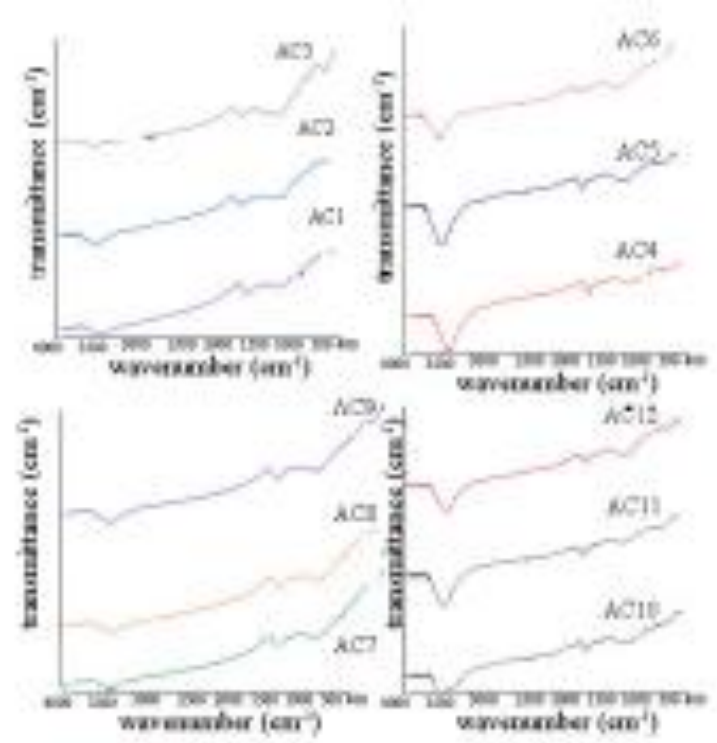

Figure 3: FT-IR spectra of activated carbons.

\section{CONCLUSIONS}

The present investigation showed that pomegranate pulp, a waste of fruit juice industries, can be effectively used as a raw material for the preparation of activated carbon. Activation temperature and impregnation ratios are effective on the porosity, surface area of activated carbons. The production of activated carbons with high surface area and highly developed micropore from pomegranate pulp is indeed of importance from the view point of economic and environmental aspects. The activated carbons produced can be effectively used as a low cost adsorbent for various environmental applications such as removing hazardous compounds from industrial wastewater and waste gases.

\section{REFERENCES}

Hendawy, A.A.,2006. Variation in the FTIR spectra of a biomass under impregnation, carbonization and oxidation conditions, Journal of Analytical Applied Pyrolysis, 75, 159.

Ioannidou, O. and Zabaniotou, A., 2007. Agricultural residues as precursors for activated carbon production-a review, Renewable and Sustainable Energy Reviews, $11,1966$.

Senthilkumar, T., Chattopadhyay, S.K. and Miranda, L.M., 2017. Optimization of Activated Carbon Preparation from Pomegranate Peel (Punica granatum Peel) Using RSM, Chemical Engineering Communications,204, 238. 
